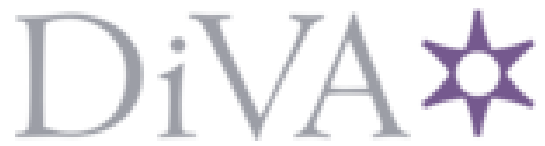

http://www.diva-portal.org

\title{
Postprint
}

This is the accepted version of a paper published in Journal of Philosophy of Education. This paper has been peer-reviewed but does not include the final publisher proof-corrections or journal pagination.

Citation for the original published paper (version of record):

Dahlbeck, J. (2019)

Education, illusions and valuable fictions

Journal of Philosophy of Education

https://doi.org/10.1111/1467-9752.12369

Access to the published version may require subscription.

N.B. When citing this work, cite the original published paper.

Permanent link to this version:

http://urn.kb.se/resolve?urn=urn:nbn:se:mau:diva-3673 


\section{Education, illusions and valuable fictions}

\section{Two parallel aims of education: protecting the common moral community and promoting the intellectual freedom of the student}

In his book Free Will and Illusion (2000), Saul Smilansky argues for a position that has come to be known in the philosophy of free will as Illusionism. Illusionism entails that libertarian free will is recognised as a false belief (i.e. a belief that cannot be convincingly grounded in a coherent metaphysical foundation), but one that is deemed so important for the safekeeping of a functioning moral community that it is worth sustaining indefinitely despite its assumed falsity. Illusionism goes to the heart of an old educational paradox identified by Nigel Tubbs in Plato's allegory of the Cave. Tubbs puts this age-old paradox in the form of a question: 'If education is enlightening, unsettling and potentially destructive, is it right to teach for this? Is it right to teach for the shadows or to prepare the path out of the Cave?' (Tubbs, 2005, p. 67).

In this article, I will argue that this paradox seems to open up for an understanding of two parallel aims of education. One aim concerns the protection of a common moral community and the other aim concerns the promotion of the intellectual freedom and autonomy of the student. Instead of settling for an understanding of two parallel aims, however, I will argue that protecting the moral community and promoting the intellectual autonomy of the truthseeking individual are intermingled practices insofar as it concerns a gradual process from understanding the world inadequately to understanding the world more adequately. Education, on this view, translates into a complex process where maintaining the stability of the moral community needs to be balanced against the benefits of debunking established yet false beliefs, but it cannot be predicated by the perpetuation of illusions.

Taking Smilansky's position of Illusionism as a starting point, I argue that while Illusionism highlights and addresses an important problem - that sometimes false beliefs can function to maintain social stability where the truth threatens to unsettle it - relying on indefinite illusions is problematic from an educational point of view. It is difficult to justify that education, being at least in part motivated by truth-seeking, should (or even could) be grounded in illusion. Taking seriously the fact that a dimension of education concerns maintaining social stability, I suggest that Spinoza's notion of fiction can complement Smilansky's view in that it can be conceived in terms of an instrument for maintaining social stability and promoting truthseeking without assuming that one end is pursued at the expense of the other.

Rather than accepting Smilansky's position (outlined below) that some false beliefs are important enough to warrant their indefinite perpetuation, I will argue that education is inimical to Illusionism insofar as the striving for a more adequate understanding of the world cannot be grounded in illusion. In place of illusion, then, I will explore the benefits of working with fiction as a means for facilitating the process whereby students shed false beliefs and gradually acquire a more adequate understanding of the world. Drawing on Spinoza's discussion on the role of fictions for social stability and in the acquisition of knowledge, I will argue that the freedom to philosophize ${ }^{1}$ hinges on the safety of the moral community from

\footnotetext{
${ }^{1}$ On Spinoza's view, the freedom to philosophize is the goal of a good state as well as the highest good of the individual.
} 
irrational attacks, and that the use of valuable fictions can provide an educational bridge between an unreflective reliance on false beliefs and the critical inquiry of unconvincing metaphysical presuppositions. Spinoza is of particular interest here because while he espouses a strong defence of the ethical value of seeking the truth in all educational endeavours, he also allows for a realistic conception of the limitations of human cognition. I will conclude that these limitations entail that fictions are necessary as they compensate for an innate privation of knowledge and that they can in fact be valuable insofar as they stimulate the imagination to strive for things that are intellectually difficult to grasp yet clearly beneficial for the striving for self-preservation.

\section{Smilansky's Illusionism}

On Smilansky's account, the notion that we can be truly responsible for our choices and actions is ultimately grounded in the illusion of a libertarian free will. Very briefly, libertarianism entails that we are responsible for our actions by virtue of being their adequate causes. Free will, in this sense, is typically construed as the ability to do otherwise. The ability to do otherwise, in turn, helps set up the important relation between free will and moral responsibility. As Peter van Inwagen puts it: 'We care about free will because we care about moral responsibility, and we are persuaded that we cannot make ascriptions of moral responsibility to agents who lack free will' (2017, p. 20). Without the ability to make ascriptions of moral responsibility it becomes difficult to pass moral judgments over actions, which in turn complicates the ascription of legal responsibility, illustrating the stakes involved.

Smilansky submits that the problem with understanding free will in terms of the ability to do otherwise is that it runs into the problem of having to explain origination. Derk Pereboom summarises the libertarian claim about origination as follows: '(O) If an agent is morally responsible for her deciding to perform an action, then the production of this decision must be something over which the agent has control, and an agent is not morally responsible for the decision if it is produced by a source over which she has no control' (2001, p. 47). Moral responsibility, in this view, appears to demand self-causation. Self-causation, in turn, is difficult to explain as it entails the assumption that we can somehow gain total independence from external causes such as our biological make-up, our upbringing, and the influence of our social milieu.

The illusion of free will that Smilansky refers to in his theory of Illusionism is the same free will that demands self-causation. Acknowledging the metaphysical implausibility of free will (construed as the ability to do otherwise), Smilansky explains his reasons for wanting to retain this illusion indefinitely as follows:

Our view of ourselves as responsible for our choices and actions, our adherence to the proper moral order, our concern for preventing injustice, our appreciation of the dedication, effort, and sacrifice of others, our capacity for self-respect these and more significantly depend upon illusion. It is not that we should delude ourselves willingly, let alone hold the required beliefs while knowing that they are illusory, but that, fortunately, these enabling illusions are in place. [...] We can see that illusion is thus positive or 'functional' (First Stage of argument), that it operates today (Second Stage of argument), and that, on balance, it would be 
a good thing if it continued to exist in a manner akin to that which it possesses today (Third Stage of argument). (Smilansky, 2000, pp. 288-289, emphasis in original)

In sum, most people believe in free will (as the capacity to do otherwise) and this, in fact, provides the basis for what Thomas Nagel (1989) calls 'our ordinary conception of autonomy' and Gregg Caruso (2012) calls 'the folk psychology of free will.' While Smilansky maintains that this ordinary notion of free will is difficult to justify philosophically - as it is difficult to provide rational explanations for self-causation and origination - it has practical consequences that are deemed important for sustaining our common moral community. It is Smilansky's contention that ordinary people should not be overtly lied to but that available philosophical arguments (illustrating the unlikeliness of a libertarian free will) should be withheld from them so as to keep them safe from dangerous information for moral and psychological reasons. This, however, puts education in a particularly tricky spot.

To the extent that education is related to truth-seeking, education appears to be particularly sensitive to Hume's warning against bending philosophical truth-seeking to the demands of moral and/or religious dogma. Hume writes: 'There is no method of reasoning more common, and yet none more blameable, than in philosophical debates to endeavour to refute any hypothesis by a pretext of its dangerous consequences to religion and morality' (Hume, 2000, p. 263/Treatise 2.3.2). At the same time, however, education is also typically held as an important site for the moral formation of young people (see for example Carr, 2003; Hand, 2018), and insofar as the common moral community is a prerequisite for moral formation, it appears to be important to safeguard it from unnecessary dangers and threats. Because much of our ordinary moral language is bound up with a libertarian understanding of free will it appears likely that debunking this fundamental belief will also affect our moral attitudes in various ways. Peter Strawson famously raises this concern, asking the following questions:

What effect would, or should, the acceptance of the truth of a general thesis of determinism have upon these reactive attitudes? More specifically, would, or should, the acceptance of the truth of the thesis lead to the decay or the repudiation of all such attitudes? Would, or should, it mean the end of gratitude, resentment, and forgiveness; of all reciprocated adult loves; of all the essentially personal antagonisms? (Strawson, 2013, p. 80)

The role of illusions, then, is to render determinism harmless and to help safeguard our moral practices and intuitions based on a libertarian understanding of free will. While Strawson addresses the threat that determinism poses to ordinary moral attitudes, Smilansky argues that the kind of naturalism Strawson proposes is unable to sufficiently deal with it. Illusionism, Smilansky claims, is better equipped for this task as it 'allows us the advantages of the libertarian picture together with the mitigating element, without full awareness either of the incoherence of the libertarian picture or the contrariness of the compatibilist and ultimate perspectives' (Smilansky, 2001, p. 92).

Smilansky's position is that (1) there is no libertarian free will; (2) compatibilism is insufficient as a basis for moral responsibility as it cannot be grounded in libertarian free will; (3) common freewill-related attitudes need to be maintained in spite of (1) and (2); and (4) because 
illusions about free will are already in place, and because the role they play is largely positive in terms of maintaining a stable moral community, Illusionism is preferable to other positions such as Strawson's reactive-naturalism (Smilansky, 2001). On Smilansky's account, Strawson's reactive-naturalism is insufficient as it relies too heavily on the assumed stability of reactive attitudes. Smilansky argues that if reactive attitudes are disconnected from a basis in the belief in free will, we risk losing ultimate-level grounding for (self-)respect that is necessary for motivating these reactive attitudes in the first place. Illusionism, in contrast, hinges on the assumption that 'people as a rule ought not to be fully aware of the ultimate inevitability of what they have done, for this will affect the way in which they hold themselves responsible' (Smilansky, 2001, p. 85).

In the present paper I am not concerned with whether libertarianism (or compatibilism) holds up to philosophical scrutiny (I have addressed the free will problem in an educational context elsewhere, see Dahlbeck, 2017; Dahlbeck, 2018a; Dahlbeck, 2018b), but with what the practical consequences of a position like Illusionism would be for education. For this reason I will focus on the tension introduced by assuming that education (as a truth-seeking endeavour) must rely on (and implicitly perpetuate) existing illusions (whatever these may be). While the occurrence of false beliefs ${ }^{2}$ may be inevitable to some extent in education, it seems counterintuitive to assume that some false beliefs are to remain hidden from the inquisitive gaze of the student (if not outright perpetuated). ${ }^{3}$ Even if this is done so as to enable 'genuine feelings of responsibility' (Smilansky, 2001, p. 87), it seems to run counter to the foundational educational aim of promoting critical inquiry.

It seems to me that Smilansky's position fundamentally undermines education if we assume that education - in a deep way - concerns the cultivation of intellectual and moral virtues. Prima facie, it is difficult to see how maintaining illusions can be reconciled with educational ideals such as intellectual and moral flourishing. In contrast, I will suggest that Spinoza offers a more educationally productive understanding of how fictions can be used to navigate between the aim of maintaining the stability of the common moral world and the aim of promoting intellectual and moral flourishing in a way that does not presuppose the indefinite perpetuation of false beliefs qua illusions and that does not assume that these two aims are separable from one another in the first place. He does this, I will argue, by demonstrating how the imagination plays an important role in the processes of human understanding and how it can be productively taken advantage of so as to curb irrationality and further a more adequate understanding of the world.

\section{The educational promise of Spinoza's use of fictions}

\footnotetext{
${ }^{2}$ Smilansky's concept of illusion 'combines the falsity of the belief with some motivational role in forming and maintaining that belief, as in standard cases of wishful thinking or self-deception' (Smilansky, 2001, p. 89). ${ }^{3}$ While Smilansky is clear that Illusionism is not about spreading lies (something that can be avoided as he claims the illusion of free will is already in place), it is clear that Illusionism is concerned with keeping uncomfortable and potentially dangerous truths away from the general public. More specifically, Smilansky argues that 'the intimacy of the connection between moral and personal integrity and beliefs about free will' illustrates that 'the danger of realizing the truth also looms large' (Smilansky, 2001, p. 87, emphasis in original). Accordingly, Smilansky concludes that given the looming danger of the truth of determinism, 'there is a prima facie case for a large measure of motivated obscurity regarding the objections to libertarian free will' (Smilansky, 2001, p. 90). It is the notion that realizing the truth is set up as a looming danger that I find especially troubling for education.
} 
While the imagination, taken in isolation, is certainly a flawed form of cognition - insofar as it does not adequately grasp the full nature of things - it is necessary and useful for compensating for cognitive limitations that are innate. Spinoza is particularly helpful here as he offers a way of explaining how the imagination works in dynamic ways and that depending on the forces that take hold of it, the imagination can inflame prejudice and foster irrationality but it can also provide a passage from irrationality to a more adequate understanding of the world. This is where education becomes important as a way of harnessing the forces of the imagination and using it for the dual purposes of creating moral stability and promoting the intellectual freedom of the individual.

Moving from the concept of illusion to the concept of fiction has the benefit of shifting focus from false beliefs (and the telling of lies) to the educational navigation of the gradual spectrum from imaginative yet incomplete understandings to a more adequate understanding of the world. In this sense, fiction seems intuitively more educationally valuable than false beliefs or illusions, even if there is no guarantee that the use of fiction enables students to gain reliable knowledge of the world. Before looking closer at the role fiction might play in the educational pursuit of truth, however, we should look at Spinoza's conception of how the imagination can benefit from fiction as a means for bridging between a confused understanding of the world to a more adequate understanding, and how this relates to the educational process of becoming ethical.

In a recent article on Spinoza's conception of civic education, Christophe Miqueu comments on the importance Spinoza places on maintaining a stable political community as a measure to protect the right of the individual to strive for an increased understanding. He writes: 'The political dimension of education is central here. The freedom to philosophize can only exist if the republic itself is reformed. This is undoubtedly one of the central points of Spinoza's republicanism' (Miqueu, 2018, p. 5). While the true purpose of the state is freedom (Spinoza, 2016a/TTP XX) (translating into the practical freedom to philosophize), there is always a price to pay for this freedom in terms of mitigating the irrational impulses of human beings. This plays into the role of fiction insofar as there is always a risk that a fiction can turn out to be precisely the kind of unattainable ideal that feeds into the myth of unconstrained personal freedom rather than providing realistic, and contextually varied, images of how freedom and virtue are best pursued in different circumstances and depending on a person's level of understanding.

That being said, there appears to be two different kinds of fiction in Spinoza's writings. There are fictions intended to bind together a moral and political community through shared narratives that appeal to the imagination of as many people as possible (in a given context), and there are fictions intended to further the striving of the individual for self-preservation and enhanced power of acting. The first kind of fiction is found in Spinoza's political writings and the second kind (primarily) in the Ethics. What is interesting to note, however, is that the two kinds of fiction are complementary insofar as they both serve the purpose of enabling a more adequate understanding of the world, albeit from two different points of view. Before looking closer at Spinoza's different conceptions of fiction it is helpful to start with unpacking his understanding of what constitutes a fiction in the first place. 
From Spinoza's perspective, all fictions depend on a privation of knowledge. If the idea feigned were to be adequately understood, it would no longer be a fiction. For something to be adequately understood means that we have access to its full causal history. If we understand how a thing has been caused, we automatically understand it to be necessarily existing. If we lack this knowledge, however, we may entertain fictions. To understand something as being possible, then, is equivalent to feigning:

I call a thing impossible whose nature implies that it would be contradictory for it to exist; necessary whose nature implies that it would be contradictory for it not to exist; and possible whose existence, by its very nature, does not imply a contradiction - either for it to exist or for it not to exist - but whose necessity or impossibility of existence depends on causes unknown to us, so long as we feign in existence. So if its necessity or impossibility, which depends on external causes, were known to us, we would be able to feign nothing concerning it. (Spinoza, 1985a, pp. 23-24/TdIE §53, emphasis added)

Fictions are not the same as illusions, however, as fictions do not have to be believed to be entertained. In fact, for Spinoza, there is an ethical value in entertaining fictions. So long as we do not have perfect knowledge of natural causation (something that we will never have) it is sometimes better to entertain fictions (that are recognised as fictions) than to maintain indefinite illusions insofar as illusions are inimical to truth-seeking whereas fictions (as we will see) can be used to further the understanding by compensating for knowledge that we lack. Accordingly, Spinoza explains that

we ought to define and explain things through their proximate causes. That universal consideration concerning fate and the connection of causes cannot help us to form and order our thoughts concerning particular things. Furthermore, we are completely ignorant of the order and connection of things itself, i.e., of how things are really ordered and connected. So for practical purposes it is better, indeed necessary, to consider things as possible. (Spinoza, 2016a, p. 126/TTP IV , 4, emphasis added)

While the notion that things are possible is to be regarded as a fiction for Spinoza, it is better - for ethical purposes - to entertain this fiction and to allow it to guide one's actions than to be left without reliable guiding principles. We should be careful, however, when we pick the fictions that we allow ourselves to be guided by. As Justin Steinberg notes, '[f]ictions, like the idea of gaining eternal love of God, the idea of an open future, or the representation of moral exemplars, might stimulate us to act in ways that are more consistent with our aims than if we acted just on our beliefs' (2018, p. 266). These fictions are not substitutes for the truth, but they can affect us in ways that are beneficial for us even if we do not see precisely why that is. So, for example, 'the idea of an open future [...] might stimulate us to act in ways that are more consistent with our aims than if we acted just on our beliefs' (ibid.). If a fiction can stimulate us in this way it constitutes a particularly valuable fiction.

While there are obviously fictions that will not have this desired effect (some fictions will rather bolster prejudice and help breed superstition), some will and these are the ones that will make for valuable educational fictions. In an educational context, fictions can span from 
the ones that are practical insofar as they help compensate for an innate privation of knowledge to the fictions that are more valuable insofar as they also offer helpful images facilitating the ethical striving for an improved understanding. These different fictions may have quite different - and even seemingly contradictory - purposes. Some fictions are mainly useful for adjusting information so that it is more readily available for the uneducated, whereas some fictions can function to support the person already striving for enlightenment.

It is important to note, however, that Spinoza is not propagating the spreading of lies through fiction, but that he proposes a use of fiction that takes into account the different levels of understanding of different people. For some people, the constant vacillation between hope and fear may need to be regulated through imaginative narratives that can establish 'a standard of conduct that all can be expected to, and indeed do, imitate' (Rosenthal, 2002, p. 235). These fictions need to speak to the experience of the people addressed in order to be persuasive. As Michael Rosenthal argues, Spinoza's sophisticated understanding of the interplay between the imagination and reason led him to suggest the use of 'imaginative universals that function to create a standard on the basis of which values can be defined and right conduct urged' (Rosenthal, 2002, p. 248). Because people are always influenced by their imagination, it makes little sense to disregard this powerful influence in the context of education. The first kind of fiction, then, is especially designed to speak to the imagination of the uneducated, whereas the second kind is specifically designed to facilitate the pursuit of truth of the educated.

The first kind also serves as an effective instrument for governing people by curbing dangerous passions that threaten the stability of the common moral community (by offering deterring images and the promise of rewards), whereas the latter kind serves as a tool for supporting the ability to understand more. As Moira Gatens remarks, '[w] hereas the philosopher uses the imagination as an aid to reason, in the case of religion it functions as a substitute for reason' (Gatens, 2012, p. 78). As I will argue in more detail below, education can be conceived to serve both ends. It is reasonable to assume that public education is necessary for governing the passive responses of the uneducated, making sure that the community is kept safe from dangerous disruptions and the general spread of dangerous passions. But there is another, perhaps more important, aim that parallels the first; that of promoting the freedom of the student through truth-seeking and the emendation of the intellect. Whereas the first aim can surely be attained with the help of 'necessary' illusions, the rationalistic character of the second aim appears to be much more difficult to reconcile with the position of Illusionism.

Some false beliefs can be treated in terms of desirable illusions, functioning mainly to uphold the collective illusions of moral responsibility and just desert, thereby curbing irrational desires that threaten the stability of the common moral community. Illusions are problematic, however, insofar as they are not susceptible to reason. Because illusions hinge on their being sustained indefinitely, they lack the flexibility of fictions that can be altered according to the demands of the particular situation and the persons involved. A fiction can be made to serve reason, and this is its great advantage over an illusion. Not all fictions will do this, however, and they will not do so automatically. For a fiction to support reason rather than inflame irrational fears and superstitions, it needs to be made into a tool easing the passage from ignorance to an increased understanding. Susan James (2010) relates Spinoza's endeavours to 
render specific fictions valuable for the ethical striving for intellectual freedom in a way that speaks directly to the refinement of fictions in education.

James sets out to trace Spinoza's investigation of how narratives can be used to further the ethico-political striving to persevere in existence throughout his philosophical work. Very briefly, Spinoza argues that the best way for people to truly perceive the benefits of peaceful coexistence is for them to arrive at a philosophically sound understanding of themselves and nature. Because this understanding is exceedingly difficult to attain, Spinoza concludes that it is advisable to employ imaginative narratives that can persuade as many people as possible of following simple rules of living, aiming at the goal of a flourishing community. The problem with some narratives is that while they may do the job as effective tools of governance for a time, they can also backfire insofar as the demand for total subordination can give rise to widespread feelings of disempowerment and anxiety, thus revealing their inherent limitations. While other narratives are more easily adaptable to different interpretations and to individual motivations, they may lack the general appeal that ensures the stability of the greater community.

Spinoza's endeavour to sketch out a fictitious model of human nature - via the free man who amounts to a fully rational person (Spinoza, 1985b/E4p66s-E4p77) - marks an attempt to construe a narrative that is appealing to the imagination without sacrificing the philosophical search for truth and understanding. In James's reading, Spinoza's fiction of the free man offers his readers 'a model of a life organized around the pursuit of philosophical understanding, and invites us, his readers, to use it to give meaning and value to what we do' (2010, pp. 265-266). The idea is that this fiction would give expression to sustainable philosophical principles in a way that can be approached in different ways depending on our level of understanding. Offering philosophical lessons without underestimating the ever-present influence of the imagination is what would make this fiction valuable from Spinoza's point of view. In conclusion, James suggests that

the way of life endorsed by reason needs to be brought within imaginative reach if it is to mold our desires and actions. The general principles around which it is organized must be made liveable by being embedded in the narratives that give meaning to what we do and shape our aspirations. (James, 2010, p. 267)

According to this conception of how to make fictions educationally valuable, the content of the fiction is less important than the extent to which that fiction can be used to illustrate the (personal and collective) benefits of living guided by reason. From Spinoza's point of view, all humans strive for an increased understanding. Being limited cognitively, however, we rely upon our imagination to fill in the blanks so to speak. The full picture of what the world is like will likely never be within our grasp and so we depend on external aids to help us. Valuable fictions - such as Spinoza's fiction of the free man - can serve this purpose by offering exemplars to strive for and to be imaginatively captivated by.

From the point of view of education, the weakness of Spinoza's account of valuable fictions is precisely that fictions appear to require a measure of rationality to be effective as an aid to reason. In education, one cannot simply assume that students are already motivated by a rational desire for an increased understanding. A big part of education concerns awakening 
this slumbering desire to learn, and this may take a long time. In addition, as I have already suggested, public education is also entrusted with the task of tempering irrational desires so as to protect the common moral world from various internal and external threats. Insofar as this may require different kinds of fiction that are more concerned with mitigating dangerous passions than facilitating truth-seeking, it begs the question of how the protection of the common moral world can be reconciled with the promotion of the desire to understand oneself and the world better in one and the same educational setting.

\section{On false beliefs and illusions in education}

In a general sense, educational practices (like most any practices) rely on tacit theoretical presuppositions of various kinds. What sets educational practices apart from most other practices is that, arguably, educators traditionally have a specific relationship to the notions of knowledge and truth and that, perhaps more importantly, they have a responsibility for ensuring the validity of the knowledge and truth-claims they introduce their students to. The problem, of course, is that few of us can adequately account for our tacit theoretical presuppositions, even when they turn out to be pivotal for the general world-view we present to others. Educators, like most anybody, reinforce certain ill-conceived notions because they are not generally well trained in the critical analysis of the everyday language of their practice. Part of the reason for this is that some powerful yet tacit theoretical assumptions correspond with an overall phenomenological experience of being in the world that would make it seem counterintuitive to question them. The pervasive idea of a libertarian free will is an example of a commonly assumed capacity that corresponds with a powerful phenomenological experience of being an agent in the world, even though, at a fundamental level, it turns out to be a highly contested assumption in a philosophical context. It is important to scrutinise this tension since our understanding of agency and personal autonomy is clearly very significant for how we conceive of the limits and scope of educational influence and educational transformation.

Perhaps it is not so surprising, then, that some false beliefs (beliefs that may have been convincingly debunked by philosophers or other specialists) linger on in educational practice. There is an important distinction to be made, however, between false beliefs that are unreflective and false beliefs that are recognised and indefinitely entertained. It is the latter kind of false beliefs that Smilansky $(2000 ; 2001)$ refers to as illusions. Whereas many false beliefs are simply misconceptions or misgivings that are perpetuated through practices that are unfortunately out of touch with recent scientific and/or philosophical advancements, some false beliefs are connected with deep-rooted moral convictions that are deemed too important to protect for metaphysical nit-picking to interfere. Just desert and moral responsibility are good examples of moral and legal notions that in a fundamental sense hinge on the efficacy of human decision-making. If the libertarian idea of free will, necessary for grounding these notions, is irrevocably debunked, then this will no doubt have serious repercussions for our shared moral world. This is where Smilansky proposes that Illusionism is not only to be preferred, but indeed necessary for sustaining a meaningful sense of morality and for protecting the human social world from the dangers of disillusion and value relativism.

Education presents an interesting challenge in this context because education, as indicated above, has a particular role to play with regards to truth-seeking, the striving for reliable 
knowledge, and for the introduction of young people to a scientifically up-to-date understanding of the world. It is important to distinguish the search for truth - through critical inquiry - from a routine reliance on generally held assumptions about the truth. The search for truth is driven by doubt - where even our most fundamental preconceptions about ourselves are allowed to be critically interrogated - whereas assumptions about certainty are generally hinged on a reluctance to venture beyond preconceived ideas. Education, from this perspective, might be said to be caught between the task of maintaining the stability of the moral community through the perpetuation of certain agreed upon preconceptions (however metaphysically incoherent) and the task of supporting the critical inquiry of the doubting student. As such, part of education strives for stability and comfort and part of it strives for (moderate) discomfort and the improvement of the understanding. Peter Roberts describes education in terms of a sometimes painful revaluation of preconceived ideas:

Education promotes not greater certainty but greater doubt - and with doubt can come despair. Education, it is often believed, is a process through which we subject our ideas to critical scrutiny. In becoming educated, it is expected that we will come to question much that was hitherto taken for granted, such that we will never be the same again. (Roberts, 2016, p. 16)

To the extent that education 'can and should promote doubt and questioning' it will also seek to 'unsettle, disturb, or disrupt the status quo' (Roberts, 2016, p. 17). At the same time as the promotion of doubt holds an intuitive appeal, it would be odd to assert that the aim of public education is to disrupt and overturn the core assumptions in which the common moral community is grounded. If nothing else, the current rise in the debate concerning moral education speaks to the important role of public education in maintaining the stability of the moral community. As has recently been pointed out by Michael Hand: 'Moral education matters because each new generation must be taught the difference between right and wrong' and it follows from this that '[t]he crucial educational task is the formation of responsible moral agents' (2018, pp. 5-6). While we might wish for a complete correspondence between 'right and wrong' and 'true and false,' the many empirical differences in how different moral communities construe their moral codes tell us that this is not the case. One way of understanding this is to make a distinction between the role of education in establishing and maintaining a functioning moral community and the role of education in promoting the search for truth. Herein lies one of the most pervasive and difficult to solve paradoxes of education. It asks: is it ever defensible to perpetuate false beliefs in education? The flip-side of this question is just as relevant however. It asks: how much should we be willing to pay for the intellectual spoils of our unrelenting quest for the truth?

The benefit of turning to Spinoza's understanding of the use of fiction is that it disrupts the seeming dichotomy - asserted by Smilansky - between maintaining the stability of the moral community and the pursuit of truth. This is so as it denies any direct value of maintaining false beliefs, while being realistic about the challenges involved in balancing between ensuring social stability and promoting moral and intellectual flourishing. Education, on Spinoza's account, is never about telling lies (knowingly or unknowingly) but about protecting the right of the individual to pursue the truth while being weary of the threats to this endeavour by people who are moved to act more by passions than by reason. As already mentioned, the 
power of fiction can be very effective in its appeal to the imagination, and for this reason the use of fiction is educationally valuable.

In an educational context, much has been written about the use of fiction. In what follows I will briefly outline two different approaches to the use of fiction in education. First, I will look at fiction in terms of its role for moral education, as a means for engaging the narrative imagination of students. Second, I will look briefly at the contested relationship between the use of fiction and the striving for reliable knowledge about the world in an educational context. Against this background of the role of fictions in education, I will then close this paper by arguing for the educational value of Spinoza's conception of fiction as offering a different route from that of Smilansky's Illusionism.

\section{The use of fictions in education}

As we have seen, Spinoza's understanding of a fiction is broad insofar as a fiction denotes any idea that is feigned (meaning that we lack the causal history to explain it). This sets it apart from a more narrow understanding where fictions represent entities that do not exist (at least in the sense of ordinary physical objects) (Kroon \& Voltolini, 2016). As Amie Thomasson notes: 'In our everyday discussions of literature we treat fictional characters as created entities brought into existence at a certain time through the acts of an author' $(1999$, p. 5). Educators use this kind of fiction in education all the time. Educators use fictions (novels, films etc.) as works of art to study in their own right and they use fictions as resources for studying and discussing things that exist outside of the fictional work in question (such as moral questions about right and wrong, justice and injustice or courage and cowardice).

But fictions may also be used by educators in a less formal sense. From Spinoza's perspective, a helpful way of describing a fiction is to compare it with a belief. Whereas beliefs are supported by other ideas (in a system of beliefs), a fiction is suspended by other ideas that do not support it. Justin Steinberg, drawing on Spinoza's distinction between fictions and beliefs, explains that fictions, unlike beliefs, are 'joined to ideas that either positively exclude the existence of the feigned idea or at least render it dubious by neutralizing its power' $(2018, \mathrm{p}$. 265). Some fictions make for powerful educational tools precisely because while they can engage us emotionally, they do not lead us into the indefinite perpetuation of illusions. According to Steinberg, this is because

powerful fictions are quite isolated - quarantined, as it were - from one's other potent ideas. When one leaves the movie theater and the immediate stimulus for the fiction is lost, there is no network of ideas that will bolster these fictions. This is true for other fictions that one knows to be false: one can feign them, and thereby temporarily (and perhaps potently) affirm them, without worrying that they will undermine one's (opposing) commitments, because, provided that no further compensatory adjustment are made that enable such ideas to gain a greater foothold in one's belief-system, there is a firm doxatic buffer that prevents them from exerting a steady influence. So, fictions, as isolated ideas, can be profoundly affirmed without being believed; unfortunately, so can rogue desires or representations of goodness. (Steinberg, 2018, p. 275, emphasis in original) 
The combination of being effective means for arousing emotions and being acknowledged as feigned, make fictions well suited for certain educational purposes. In terms of providing a safe yet intellectually and emotionally stimulating setting for discussing difficult moral concerns, fictions can function by divorcing a particularly sensitive subject from its real-life context and by doing so, can alleviate the personal engagement of the students without subjecting them to unnecessary emotional pain. For example, a fictional account can provide an emotionally engaging example for talking about bullying without situating the problem in the actual life-world of the students. This may help them engage with the problem intellectually, and it can keep them from being carried away by powerful passive affects such as moral indignation and vengeance.

In a recent article, David Carr (2018) has explored the educational promise of moral exemplification of literature and art. Unlike the emulation of real-life exemplars or role models, characters drawn from literature and art can have the benefit of allowing for a critical distance between the one admiring and the one admired. On Carr's account, this can offer a way of avoiding unreflective admiration of people who are 'admired for less than morally admirable qualities' (Carr, 2018, p. 1). The problem with exemplification and role-modelling is that imitation may not latch on to specifically moral qualities as these are not always deemed immediately attractive. In short, 'what is morally good may not be attractive and what is naturally attractive may often be far from good' (ibid.). Because of this, there is no guarantee that moral exemplars are emulated in ways that reflect the aspects that are deemed morally exemplary. In response to this problem, Carr suggests that literature and art can offer an opportunity for 'critical exploration of good and bad human character' (Carr, 2018, p. 9) in a way that not only serves to illustrate exemplary ways of being, but, just as importantly, opens up avenues for critical self-reflection and other-understanding. The benefit of working with literary and artistic exemplars, on Carr's account, is that these narratives can be adjusted to the tendencies of human imagination, and so they are taken to be less vulnerable to distortions.

Another illuminating exploration of the moral impact of narratives and the narrative imagination may be found in chapter 3 of Martha Nussbaum's Cultivating Humanity (1997). Here, Nussbaum argues for the educational and moral importance of cultivating the imagination via different, culturally diverse, narratives that will allow us to explore various perspectives beyond our own narrow scope. This, she claims, is important as it will help equip young people for a more dynamic form of democratic citizenship where the ability to empathize with, and better understand, those that are construed as different from us is deemed essential. In this way, fiction may be used to reach beyond superficial differences, often blocking our view in everyday life, in order to get to the deeper truth of our fundamental similarities as human beings as well as unveiling real differences that result from our various experiences and cultural backgrounds (pp. 111-112). Fictional narratives, in this setup, becomes a crucial vehicle for expanding our horizons, and in extension, for combating prejudice and small-mindedness. Narratives function by allowing us to explore different experiences of the world (not readily available to us) while at the same time providing a means for inner self-cultivation through the education of the imagination. 
Both Carr and Nussbaum argue, in different ways, for the benefits of turning to fictional narratives in moral education. The fictions that are deemed especially valuable, in this context, are fictions that can be employed to educate the imagination in ways that curb irrationality and fear and that promote human freedom through a better understanding of the human condition. Because good fictional narratives engage our imagination, they may tap into our psychological make-up in ways that allow us to critically judge the behaviour of others as well as to reflect on our emotional response to others. Ideally, this may help us shed distorted and stereotypical understandings of those different from us as well as focus on cultivating our selfunderstanding so as to arrive at a more realistic conception of ourselves.

Besides functioning as an aid to the moral imagination, fictional accounts can also be used to represent historical events in a way that engages the imagination and forges strong emotional links between the past and the present. Fictional representations of history can function as placeholders of knowledge that we lack, adding emotional depth to the inherent dryness of archival knowledge. Knowing that the story is feigned does not take away the sense that history can be represented in ways that are exciting and that can hold great appeal to the imagination. Being initially grasped by the story-arc, the students can then go on to find out more about the factual knowledge that was being used as building blocks of the narrative. This, of course, assumes that the use of fiction is a reliable way of instigating the quest for knowledge about the world.

A relevant problem raised in a recent article by Todd Jones (2019) concerns the gap between the assumption that good fiction will allow students a unique window into deep moral truths and the degree to which fiction can be said to adequately portray the world so as to enable the forming of reliable knowledge about it. This gap is relevant to address here as it connects with Spinoza's concerns about the ability of the human imagination to bridge between inadequate and adequate ideas. Generally, we might want to make a distinction between fictional accounts that are presented as trustworthy portrayals of the world and fictional portrayals that are claimed to be morally poignant. There is, however, a clear connection between the degree of trustworthiness and the degree of moral value of a fictional narrative. For a fictional account to have moral value for us, it would seem that we would need to be justified in believing in it. If someone successfully debunked my belief that bullies are deeply insecure (an example given by Jones) it would not seem morally defensible for me to continue to attribute a bully's behaviour to his or her insecurity, and to treat him or her accordingly. Insofar as justified beliefs correspond with reliable knowledge about the world, moral formation seems to require a degree of reliable knowledge about the world.

However, Jones claims that knowledge about the world cannot be reliably gained by simply reading fiction. Instead, reading fiction must be supplemented by activities specifically designed to 'turn ideas suggested in fiction into justified knowledge' (Jones, 2019, p. 10). There is a sense then that reading fiction might be a starting point for beginning to understand something better, but that in order for this understanding to develop, students cannot simply be consumers of fiction. Accordingly, Jones suggests that ' $f$ ] iction could easily make people interested in and curious about things that they had never been before, had they not read the fiction. They could then come to have justified beliefs about these matters if, with their curiosity thus aroused, they are inspired to do some further investigation' (Jones, 2019, p. 3). Spinoza regards fiction as a way of activating the imagination to start making connections 
between different affective states and things and events that were previously not connected. These connections, in turn, can be calibrated and enforced by a more adequate understanding of the world. It is not that fiction can render our understanding of the world more adequate, but that fiction can appeal to our imagination in a way that makes us want to understand the world better.

Not all fiction will do this however, and not all ways of employing fiction are equally productive. Spinoza's distinction between the fictions that can be used to curb irrational responses and the fictions that can be used to promote human flourishing is helpful in this context as it offers a conception of how different educational situations call for different fictions. Above are just a few examples of how fictions are and can be used in an educational setting. Admittedly, we will now move on to a domain where it is much less clear that we are dealing with fictions at all. This is partly because some fictions are so deeply engrained in our common-sense that they turn into false beliefs and are no longer immediately recognisable as fictions. Partly it is because the representational content is less likely to be categorised as a conventional fiction in the sense that it does not represent non-existent physical objects (c.f. Kroon \& Voltolini, 2016), but rather an idea about something whose existence we have good reasons to doubt.

\section{Necessary illusions or valuable fictions?}

Spinoza's understanding of the use of valuable fictions is especially attuned to the educational challenge posed by Smilansky's Illusionism. Even if we, for the sake of the argument, grant that the ordinary belief in free will qualifies as a false belief, Spinoza's understanding of a valuable fiction allows the social benefits of this belief to be reaped without subscribing to indefinite Illusionism. Illusionism, at bottom, requires that part of our knowledge about the world is kept in the dark. Smilansky is adamant that Illusionism is not about flat out lying to people, but at the same time, as we have seen, a precondition for the continued currency of illusions is that they are not debunked or explicitly called out as illusions. Spinoza's fictions, however, can be employed as provisional placeholders for knowledge that we lack and they can be acknowledged as fictions without losing purchase in the sense that illusions will. Where illusions automatically lose their purchase when they are called out as illusions, fictions can be recognized as fictions and still be educationally valuable.

Whether or not the ordinary belief in free will is to be considered a genuine false belief, we might see how certain aspects of our everyday behaviour and reactive attitudes (that are ultimately grounded in the idea of a free will) are helpful in terms of maintaining a stable moral community. Whereas Smilansky assumes that this requires the existence of necessary illusions, Spinoza's reasoning seems to offer us a different path. Spinoza assumes that much of our understanding of the world is flawed and that a central part of becoming educated (as well as becoming ethical) is to become aware of this and to try to gradually amend it. This does not mean remaining in a state of acting 'as if' we understood things that we do not, but it means taking into account the fact that we are not perfectly rational beings, but beings who need to make use of our imagination in order to compensate for innate cognitive limitations. Fictions can allow us to affirm ideas provisionally, but they do not hinge on the assumption that these ideas must be entertained indefinitely. 
As we saw earlier, many fictions are useful mainly insofar as they engage our imagination. They can help us act in accordance with ideals even when we do not fully understand why we should do this. So long as doing so keeps us from causing one another harm everything is well and good. What it does not do, however, is help us understand more about ourselves and the world. They help compensate for a privation of knowledge without being able to replace it. They may even be dangerous insofar as they can be joined with established prejudices such as the notion that certain groups of people have a natural disposition to morality whereas others do not. This is where the distinction between ordinary and valuable fictions becomes important. Ordinary fictions can serve as temporary placeholders for reason (allowing the imagination to gain the upper hand) whereas valuable fictions can be employed as tools for furthering our understanding while acknowledging our natural limitations as cognisant beings. Both, then, are means towards the same goal, but their utility differ depending on the level of the student's understanding.

Following Smilansky, educators can make use of existing illusions in order to instil a moral code in the young and uneducated. This moral code does not help them further their understanding of the world but it can help establish certain robust moral ground-rules that are important for the stability of the common moral community. On the other hand, if these allegedly necessary illusions are treated in terms of fictions they will take on a decidedly different appearance. They will lose some of their seeming inviolability and gain a sense of variability. It is precisely the variability of fictions that make them educationally powerful. Insofar as people are different from one another, people respond differently to different narratives. Because fictions are temporary placeholders of truth (and not necessary illusions) they can be substituted by other fictions over time: fictions that are deemed more meaningful and more appropriate for shaping our aspirations and desires (as Susan James would have it). It is not that safeguarding our common moral world is not important, but that the things we do to safeguard it cannot be allowed to counter the educational aim of pursuing the truth. This hinges, of course, on the ability of the educator to judge between fictions that are manipulative and dangerous, fictions that are mainly beneficial for the safeguarding of the common moral world, and fictions that are particularly useful as imaginative tools for facilitating truth-seeking. As Moira Gatens and Genevieve Lloyd have pointed out:

The fictions which bind together communities are not always deliberately fabricated falsehoods propagated by those who stand to gain by them. Rather, social fictions may be distorted or imaginative but genuine attempts to grasp the complex relations within and between collective bodies, and between the present and past history of those collective bodies. (Gatens \& Lloyd, 1999, p. 90)

Appreciating the educational value of social fictions can introduce a viable bridge between the two seemingly contradictory aims of education. Instead of conceiving of two separate aims, we might see how different social fictions can be employed in education to satisfy different demands. Assuming that there are illusions that must be indefinitely preserved is decidedly different insofar as it introduces an element foreign to education: it creates an unbridgeable chasm between the socio-political needs of a society and the individual's desire to learn more about the world.

\section{Reconciling the two seemingly contradictory aims of education}


Spinoza's use of fiction allows for metaphysical questions to be investigated in education, whereas Smilansky's Illusionism appears to obstruct truth-seeking where truth-seeking and necessary illusions collide. From a Spinozistic perspective there are certainly false beliefs, and many of these are troubling insofar as they bring about social practices that are troubling. At the same time, a basic tenet of Spinoza's understanding of what it is to be human is that we are severely limited cognitively and that we are therefore always more or less stumbling in the dark. To strive to understand things better does not mean that we are automatically enlightened, and it is not self-evident that philosophers are automatically more enlightened than other people. In fact, part of the problem for Spinoza is that many philosophers tend to establish an idealized image of what it is to be human and continue to construct political ideals from the basis of such an idealized image. In his unfinished Political Treatise he writes:

Philosophers conceive the affects by which we're torn as vices, which men fall into by their own fault. That's why they usually laugh at them, weep over them, censure them, or (if they want to seem particularly holy) curse them. They believe they perform a godly act and reach the pinnacle of wisdom when they've learned how to praise in many ways a human nature which doesn't exist anywhere, and how to bewail the way men really are. They conceive men not as they are, but as they want them to be. That's why for the most part they've written Satire instead of Ethics, and why they've never conceived a Politics which could be put to any practical application, but only one which would thought a Fantasy, possible only in Utopia, or in the golden age of the Poets, where there'd be absolutely no need for it. (Spinoza, 2016b, p. 503/TPI, 1)

Striving for a more realistic conception of what it is to be human means taking into consideration the innate limitations of human cognition. It means understanding that humans are neither fully rational nor fully irrational. The purpose of using fictions in education is not to supress truth-seeking, but to acknowledge the interdependency of reason and the imagination and to offer ways of communication between these two aspects of human cognition. Insofar as Illusionism is asserting the benefits of maintaining some illusions it also (albeit inadvertently) ends up celebrating ignorance. While maintaining illusions may appear necessary from a particular philosophical and political standpoint, it assumes that some philosophers have the prerogative of identifying false beliefs that others should either accept as true or simply remain oblivious of. If education is oriented towards truth-seeking, where do we draw the line between the kinds of metaphysical queries that are safe to investigate and the ones that are not? It seems to me that Spinoza's use of fictions offers a more productive - and educationally apt - approach. It admits that there are many things of which we know very little, but that we may need to accept provisionally in order to maintain social stability. It also assumes, however, that fictions are provisional and that they can be adjusted to our level of understanding. No fiction, in this sense, is a permanent placeholder for the truth, but a temporary vehicle for the imagination to make use of in order for the intellect to grasp that which is slightly beyond its reach.

In order to see how the two seemingly contradictory aims of education suggested in this paper can be reconciled it helps to conceive of education not in terms of two conflicting practices, but in terms of a complex process where seemingly different ideals are brought together. On 
the one hand, education concerns the protection of the overall well-being of the collective. From this perspective, education helps ensure the relative stability and peace of the common moral community. Part of this involves engaging the imagination of students by fictions that help express simple moral rules in a forceful way. These fictions are problematic to sustain indefinitely to the extent that they demand that we suspend difficult metaphysical questions, making them seemingly inimical to the critical inquiry of our common-sense beliefs.

At the same time, education also concerns the individual's striving for an improved understanding of the world. This educational practice goes beyond institutional schooling as it is directed at the flourishing of the individual guided by reason. The driving force behind this practice is to cultivate the understanding through the process of doubt. By subjecting ideas to critical doubt, false beliefs may be rejected and some fictions can be revealed to harbour elements that are not as innocent as we may have believed them to be. Persons guided by reason are not, however, insulated from the influence of the imagination. On the contrary, the imagination is necessary in order to create a meaningful context wherein ideas can be critically evaluated and reformed. Valuable fictions are fictions that can help alleviate this process by supplying a meaningful narrative allowing us to make sense of the personal striving for an increased understanding in relation to the striving of others.

Those who strive for an increased understanding through the critical re-evaluation of common-sense beliefs need protection from irrational attacks on their right to pursue their intellectual labour. One way of securing this right is by making sure that the majority abides by the principles of the common moral community. Because the majority are not likely to do this unless persuaded by means other than those of philosophical reasoning, education needs to engage imaginative means to illustrate the importance of abiding by stipulated moral principles even when these moral principles are poorly understood. This is a starting point for all education insofar as no educational endeavour can start in abstract philosophical reasoning, but it is also a way of protecting those who strive for a better understanding of themselves and the world so that they can pursue these ends unthreatened by the rest. This also seems to be the premise for Smilansky's Illusionism. What Spinoza's understanding of fiction has to offer, however, is a viable passage between maintaining social stability and truth-seeking. This is important as it can help raze the barrier between those who recognize illusions as false beliefs and those who do not.

Assuming that the strong hold of false beliefs can (and should) be broken through education would be to underestimate the power of the emotions and the creative input of the imagination. At the same time, supposing that education must respect existing illusions would be to violate the natural striving for an increased understanding of the world. This leaves education with the difficult task of balancing between maintaining practices deemed important for social stability and impelling students to make use of their imagination to challenge their preconceived notions about the world. Because of the tension inherent to this setup, it is useful to assume that the critical endeavour to re-evaluate common-sense beliefs can only be realised once the basic ground-rules of a common moral community is in place. If this is so, then ordinary beliefs (such as the folk-psychological belief in free will) can be used to secure social stability, ensuring that valuable fictions can be employed to safely challenge the rigidity of our pre-theoretical assumptions so that they do not stagnate and become a threat to the same moral community that they are set up to protect. This, however, can never 
be done if education is forced to turn a blind eye towards some beliefs because debunking them is deemed morally damaging.

\section{References}

Carr, D. (2003) Making Sense of Education: An Introduction to the Philosophy and Theory of Education and Teaching (London, Routledge).

Carr, D. (2018) Moral exemplification in narrative literature and art. Journal of Moral Education, DOI: 10.1080/03057240.2018.1463201.

Caruso, G. D. (2012) The folk psychology of free will: an argument against compatibilism.

Kriterion: Journal of Philosophy, 26(1), pp. 56-89.

Dahlbeck, J. (2017) Education and the free will problem: a Spinozist contribution. Journal of Philosophy of Education, 51(4), pp. 725-743.

Dahlbeck, J. (2018a) Education and Free Will: Spinoza, Causal Determinism and Moral Formation (London, Routledge).

Dahlbeck, J. (2018b) Becoming virtuous: character education and the problem of free will. In P. Smeyers (ed.) International Handbook of Philosophy of Education (Dordrecht, Springer), pp. 921-936).

Gatens, M. (2012) Compelling fictions: Spinoza and George Eliot on imagination and belief. European Journal of Philosophy, 20(1), pp. 74-90.

Gatens, M. \& Lloyd, G. (1999) Collective Imaginings: Spinoza, Past and Present (London, Routledge).

Hand, M. (2018) A Theory of Moral Education (London, Routledge).

Hume, D. (2000) A Treatise of Human Nature (eds. D. F. Norton \& M. J. Norton) (Oxford, Oxford University Press).

James, S. (2010) Narrative as the means to freedom: Spinoza on the uses of imagination. In Y. Y. Melamed \& M. A. Rosenthal (eds.) Spinoza's 'Theological-Political Treatise': A Critical Guide (Cambridge, Cambridge University Press), pp. 250-267.

Jones, T. (2019) Will students gain knowledge of the world by reading fiction? Theory and Research in Education, DOI: 10.1177/1477878519832675.

Kroon, F. \& Voltolini, A. (2016) Fiction. The Stanford Encyclopedia of Philosophy (Winter 2016 Edition), Edward N. Zalta (ed.), URL <https://plato.stanford.edu/archives/win2016/entries/fiction/>. 
Miqueu, C. (2018) Spinoza on civic education. In M. A. Peters (ed.) Encyclopedia of Educational Philosophy and Theory (Singapore, Springer).

Nagel, T. (1989) The View From Nowhere, New ed. (Oxford, Oxford University Press).

Nussbaum, M. C. (1997) Cultivating Humanity: A Classical Defense of Reform in Liberal Education (Cambridge, MA, Harvard University Press).

Pereboom, D. (2001) Living Without Free Will (Cambridge, Cambridge University Press).

Roberts, P. (2016) Happiness, Hope, and Despair: Rethinking the Role of Education (New York, Peter Lang).

Rosenthal, M. A. (2002) Why Spinoza chose the Hebrews: The exemplary function of prophecy in the Theological-Political Treatise. In L. Goodman \& H. M. Ravven (eds.) Jewish Themes in Spinoza's Philosophy (New York, SUNY Press), pp. 225-260.

Smilansky, S. (2000) Free Will and Illusion (Oxford, Oxford University Press).

Smilansky, S. (2001) Free will: From nature to illusion. Proceedings of the Aristotelian Society, Vol. 101, pp. 71-95.

Spinoza, B. (1985a) Treatise on the Emendation of the Intellect. In E. Curley (trans. and ed.) The Collected Works of Spinoza, Vol. 1 (Princeton, Princeton University Press), pp. 7-45.

Spinoza, B. (1985b) Ethics. In E. Curley (trans. and ed.) The Collected Works of Spinoza, Vol. 1 (Princeton, Princeton University Press), pp. 408-617.

Spinoza, B. (2016a) Theological-Political Treatise. In E. Curley (trans. and ed.) The Collected Works of Spinoza, Vol. 2 (Princeton, Princeton University Press), pp. 65-354.

Spinoza, B. (2016b) Political Treatise. In E. Curley (trans. and ed.) The Collected Works of Spinoza, Vol. 2 (Princeton, Princeton University Press), pp. ???

Steinberg, J. (2018) Two puzzles concerning Spinoza's conception of belief. European Journal of Philosophy, 26(1), pp. 261-282.

Strawson, P. F. (2013) Freedom and resentment. In G. Watson (ed.) Free Will, 2nd ed. (Oxford, Oxford University Press), pp. 72-93.

Thomasson, A. L. (1999). Fiction and Metaphysics (Cambridge, Cambridge University Press).

Tubbs, N. (2005) Philosophy of the Teacher (Oxford, Blackwell Publishing).

Van Inwagen, P. (2017) Thinking about Free Will (Cambridge, Cambridge University Press). 